\title{
TRAJETÓRIAS ESCOLARES DE ADOLESCENTES EM CONFLITO COM A LEI
}

\author{
Marina Rezende Bazon* \\ Jorge Luiz da Silva** \\ Renata Martins Ferrari***
}

RESUMO: O objetivo do presente estudo foi descrever o percurso e caracterizar as trajetórias escolares de adolescentes em conflito com a lei no tocante às suas experiências educacionais. Participaram seis adolescentes em cumprimento de Medida Socioeducativa e seus respectivos responsáveis. Coletaram-se informações em 22 estabelecimentos educacionais frequentados pelos mesmos, desde o início de suas vidas escolares, em complementação às entrevistas semiestruturadas realizadas. A análise qualitativa indicou a existência de dois padrões de trajetórias de escolarização, sendo um marcado pela descontinuidade na qualidade das vivências escolares, com um período inicial positivo, que torna-se negativo em seguida; e outro, cuja marca é a continuidade preponderantemente negativa da experiência, desde o início. Implicações dessas trajetórias ao surgimento e manutenção de conduta infracional são discutidas.

Palavras-chave: Adolescente em Conflito com a Lei; Ajustamento Escolar; Desenvolvimento.

\section{SCHOOL TRAJECTORIES OF ADOLESCENTS IN CONFLICT WITH THE LAW}

ABSTRACT: In this study, we aimed to describe and characterize school trajectories of adolescents in conflict with the law with regard to their educational experiences. Six adolescent offenders and their respective guardians participated in the study. Information was collected in 22 educational institutions frequented by the adolescents since the beginning of their school lives, complementing the semi-structured interviews. Qualitative analysis indicated the existence of two patterns of school trajectories: one marked by discontinuity in the quality of school experiences, with a positive beginning that becomes negative; and another whose experience is predominantly negative from the beginning. Implications of these trajectories to the emergence and maintenance of delinquent conduct are discussed.

Keywords: Teenager in Conflict with the Law; School Adjustment; Development.

\footnotetext{
*Doutora em Psicologia pela Universidade de São Paulo (USP) e professora do Programa de Pós-graduação em Psicologia da Faculdade de Filosofia, Ciências e Letras de Ribeirão Preto da Universidade de São Paulo (FFCLRP/USP). E-mail: mbazon@ffclrp.usp.br

* * Mestrando em Psicologia pela Faculdade de Filosofia, Ciências e Letras de Ribeirão Preto (FFCLRP) da Universidade de São Paulo (USP). E-mail: jorgelsilva@usp.br

* * Graduada em Psicologia pela Faculdade de Filosofia, Ciências e Letras de Ribeirão Preto (FFCLRP) da Universidade de São Paulo (USP). E-mail: r_m_ferrari@hotmail.com
} 


\section{INTRODUCุÃO}

A apresentação de comportamentos de risco, incluindo o cometimento de algum ato infracional, na adolescência, é parte de um processo estatisticamente normativo (MUN; WINDLE; SCHAINKER, 2008). Há, entretanto, adolescentes que se envolvem com a prática de atos infracionais de modo mais sério, seja pela frequência e/ou pela gravidade das ações. O comportamento nesse subgrupo encontra-se, geralmente, associado à sua exposição a inúmeros fatores de risco, situados em diferentes contextos: família, escola, grupo de pares e no contexto da comunidade de residência (FORMIGA, 2010; JANOSZ; LEBLANC, 1999; LARANJEIRA, 2007; LILJEBERG et al., 2011; ZHANG et al., 2010).

Dentre os diversos fatores, a experiência escolar negativa desponta na literatura como um dos preditores mais significativos do envolvimento infracional sério, na adolescência (ZHANG et al., 2010). Já na década de 90, LeBlanc (1994) demonstrou que variáveis escolares se sobrepunham às variáveis familiares na explicação oficial e na explicação dada pelos próprios adolescentes para o seu envolvimento com a atividade infracional. Esse autor se utilizou de diversos estudos empíricos para verificar que a prática persistente de delitos na adolescência associava-se, primeiramente, a variáveis relativas à escola e, depois, à família. De modo geral, os adolescentes em conflito com a lei apresentam baixo desempenho e interesse pela escola e elevadas taxas de evasão escolar.

Oliveira e Assis (1999), em seu turno, denunciaram o flagrante afastamento do ambiente escolar e um preocupante índice de analfabetismo apresentado pelos adolescentes com passagens pelo Sistema de Justiça no Brasil. Em 2002, um total de 51\% dos adolescentes com medida de internação estavam fora da escola no momento da apreensão e 6\% não eram alfabetizados (ASSIS; CONSTANTINO, 2005). Em 2011 esses números teriam aumentado, respectivamente, para 57\% e 8\% (CONSELHO NACIONAL DE JUSTIÇA, 2012).

Outro estudo, realizado por Gazignato (2006), revelou, com base na análise de dados de arquivos da Fundação Casa, que entre 1950 e 2002 houve um aumento progressivo no grau de escolaridade e nos anos de estudos dos adolescentes, embora a defasagem escolar tenha permanecido uma tônica. À época da pesquisa, a escolaridade dos adolescentes internados 
se concentrava na segunda etapa do ensino fundamental (entre $6^{\circ}$ e $9^{\circ}$ anos) em contraste às idades de concentração da amostra, situadas entre 15 e 17 anos, denotando também o problema da evasão. $\mathrm{O}$ aspecto mais interessante evidenciado por essa pesquisa, contudo, é o de que o aumento da escolaridade dos jovens se fez acompanhar por um aumento real do número de adolescentes praticando delitos e de gravidade dos atos, indicando que frequentar a escola, per si, não é suficiente para prevenir a conduta infracional, havendo necessidade de entender melhor a vivência escolar desses jovens (TOLEDO; BAZON, 2005).

No período da adolescência, devido às diversas alterações psicossociais, com a busca por maior liberdade e autonomia, a influência da família começa a declinar. A família não perde sua função socializadora, mas as relações estabelecidas fora do reduto familiar, nesse período da vida, passam a ocupar uma posição de destaque. A escola e o grupo de pares passam, então, a se destacar enquanto instâncias de socialização, com maior possibilidade de influência sobre o comportamento dos adolescentes (CALDWELL; STURGES; SILVER, 2007). Assim, se a experiência escolar é positiva, é nesse ambiente que os adolescentes investem boa parte de seu tempo diário, participando de atividades educacionais que favorecem o desenvolvimento cognitivo, emocional e social (MASCHIA et al., 2008). Uma boa vinculação à escola desponta como um dos fatores protetivos mais robustos ao engajamento sério de jovens com a prática de delitos (LEBLANC, 1994; LILJEBERG et al., 2011; VAN DER LAAN; BLOM; KLEEMANS, 2009).

Todavia, o processo de adaptação escolar é um desafio. De acordo com Janosz e LeBlanc (1999), nas sociedades ocidentais prepondera uma modalidade pedagógica que preconiza a submissão dos alunos a um processo de ensino uniforme, centrado nas capacidades cognitivas e no domínio das emoções, da imaginação e da sensibilidade. Eles precisam se adaptar ao que lhes é instituído, cumprir, em termos de aprendizagem e de conduta, o que é esperado, pois a avaliação se dá em função dos conhecimentos adquiridos e do grau de conformidade comportamental que apresentem. Portanto, é preciso acatar as exigências impostas pela escola, se submetendo às normas disciplinares, aceitando o funcionamento hierárquico, os conteúdos não interessantes e a competição, sendo que o sistema escolar tende a desconsiderar diferenças individuais, socioeconômicas e/ou culturais dos estudantes. 
Nesse panorama, alguns não conseguem atender a todas as exigências. As dificuldades e a consequente desmotivação podem conduzi-los a fracassos na aprendizagem, bem como à desistência dos estudos. Desse modo, seus objetivos, estrutura e métodos pedagógicos conduzem à ausência ou à perda do sentido e do valor da escolaridade (JANOSZ; LEBLANC, 1999). A evasão escolar, em seu turno, traz como consequência o aumento da vulnerabilidade do jovem, sobretudo se, em alternativa à escolarização, este não conseguir uma inserção satisfatória no mercado de trabalho, o que é tanto mais provável quanto mais ele possua poucos anos de escolaridade (JANOSZ et al., 2000). A baixa escolaridade diminui as chances de se conseguir empregos mais bem remunerados e aumenta a de viver na pobreza e depender economicamente de benefícios sociais (ZHANG et al., 2010).

Considerando-se que a conduta infracional se manifesta sob determinadas formas de inadaptação, percebe-se que ela pode se desenvolver ou ser potencializada pela experiência negativa de escolarização (DISHION et.al., 2003; LARANJEIRA, 2007; LEBLANC, 2006; PRIULI; MORAES, 2007). Os aspectos da vivência escolar mais fortemente associados à conduta infracional incluem o baixo desempenho, relação conflituosa com pares e professores, e punições reiteradas e severas. Em termos dinâmicos, um baixo desempenho concorre para o enfraquecimento do vínculo escolar, mediante o aumento de sentimentos de rejeição e de exclusão, decorrentes da frustação em relação à capacidade para a aprendizagem. A qualidade das relações entre o aluno e os professores e entre o aluno e seus pares também é importante para a vinculação à escola, e quando negativa pode impactar o desempenho escolar e o comportamento social, no sentido deste tornar-se problemático. Com isso, têm-se incrementadas as chances de ser sancionado, em virtude das regras escolares, o que, por sua vez, fragiliza a vinculação escolar (JANOSZ; LEBLANC, 1999; WYNNE; JOO, 2011).

Ademais, é provável que na escola ocorram também aprendizagens de comportamentos divergentes e infracionais devido à socialização entre pares (estudantes) apresentando dificuldades semelhantes, e que alguns estímulos no contexto escolar promovam o aparecimento e a manutenção dessa socialização negativa (FRÍAS-ARMENTA; LÓPEZ-ESCOBAR; DÍAZ-MÉNDEZ, 2003). Assim, a escola influencia a conduta do aluno, através de sua organização, clima institucional e práticas, sendo que os aspectos envolvidos nessa dinâmica ajudam a elucidar as relações que melhor 
predizem a desadaptação escolar, mais do que status socioeconômico, estrutura familiar, ansiedade ou as capacidades intelectuais (JANOSZ; LEBLANC, 1999).

É importante conceber que o envolvimento de um adolescente com a prática de delitos é um problema que se desenvolve, que se constrói na relação desse com o seu entorno e, como demonstrado até então, a escola é uma das instâncias em que as interações estabelecidas têm importante participação na construção das trajetórias. Os adolescentes em conflito com a lei apresentam dificuldades escolares, em um contexto mais geral de problemas relativos à educação, em que a escola também parece não ter recursos para atendê-los adequadamente (TOLEDO; BAZON, 2005). Por isso a relação jovem-infrator-escola deve ser mais bem conhecida/ compreendida, considerando-se, especialmente, a percepção que o próprio adolescente tem dela.

Em um levantamento realizado em bases de dados internacionais (Web of Science, PsycINFO e LILACS) e nacional (Scielo) constatou-se a escassez de trabalhos nesse eixo específico. $\mathrm{Na}$ totalidade foram identificados apenas quatro estudos que se dedicaram exclusivamente à experiência escolar de adolescentes em conflito com a lei. Os dois estudos nacionais recuperados (SILVA; SALLES, 2011; TEIXEIRA; ONOFRE, 2009) tratam o tema considerando simultaneamente a percepção de professores e dos adolescentes acerca de suas experiências escolares. De maneira geral, identificaram trajetórias escolares marcadas por processos explícitos e/ou implícitos de exclusão do ambiente escolar, nos quais se destacam a não aprendizagem, problemas disciplinares e punições recorrentes. Todavia, identifica-se que os dois estudos em pauta não priorizaram a investigação de aspectos específicos da trajetória escolar que poderiam se associar à conduta infracional, de modo mais sistematizado, pois se apoiaram no relato espontâneo dos adolescentes. Também não se detiveram na investigação do caráter processual e dinâmico da experiência desses jovens, o que é decisivo para uma melhor compreensão das diferentes vivências e significações atribuídas aos eventos escolares no decorrer da escolarização.

Os dois estudos internacionais, realizados nos Estados Unidos (ASHKAR; KENNY, 2009; SANDER et al., 2010), abordam o tema mais pormenorizadamente, considerando prioritariamente a percepção dos próprios adolescentes, porém complementando as informações com dados 
provenientes de suas respectivas escolas e famílias. Consideram igualmente a multiplicidade de configurações potencialmente presentes no percurso escolar, bem como adotam uma perspectiva mais abrangente em termos da quantidade de aspectos investigados, o que oportuniza a obtenção de resultados mais completos. Em síntese, os resultados descrevem trajetórias escolares marcadas fundamentalmente por dificuldades de relacionamento com professores, não aprendizagem, exposição ou participação em situações de violência, baixa frequência, desrespeito às autoridades escolares e conflitos familiares.

A despeito das importantes informações acerca da relação entre escolarização e envolvimento sério com a prática de atos infracionais, pouco, ainda, se sabe sobre o percurso escolar de adolescentes em conflito com a lei e como eles experienciam o processo de escolarização na realidade nacional. Assim sendo, para melhor entender essa problemática torna-se necessário estudar como tais processos ocorrem, verificando quais aspectos escolares podem influenciar o comportamento do jovem, além de compreender como esse os vivencia e percebe. Nessa direção, os objetivos que nortearam o estudo relatado foram os de descrever o percurso e caracterizar as trajetórias escolares de adolescentes em conflito com a lei no tocante às suas experiências educacionais, ao modo como vivenciaram o processo de escolarização.

\section{MÉTODO}

Com vistas aos objetivos propostos, empregou-se a abordagem qualitativa, uma vez que os delineamentos qualitativos permitem a obtenção de dados pormenorizados do contexto de vida dos sujeitos investigados, possibilitando a análise das interações que estabelecem, dos significados atribuídos às experiências vivenciadas, bem como das influências delas decorrentes (ZHANG et al., 2010). Dentro disso, adotou-se a Abordagem Biográfica, a qual possibilita uma compreensão mais aprofundada das experiências de vida dos sujeitos, resultantes das interações destes com o contexto social ao longo do tempo (CARRA, 2001). Nessa perspectiva, o material biográfico primário remete ao ponto de vista dos próprios sujeitos sobre sua história de vida. Sumariamente, o foco da coleta de dados recaiu sobre as experiências relacionadas à escolarização. 


\section{PARTICIPANTES}

Participaram da pesquisa seis adolescentes em conflito com a lei, com idade entre 14 e 18 anos. Considerando-se o quesito "estar estudando", somado a fato de "apresentar um envolvimento com prática de atos infracionais mais sérios", ou seja, um "comportamento infracional persistente", se recrutou para o estudo adolescentes que tinham dois ou mais delitos oficiais, pelos quais haviam sido processados, tendo recebido medidas socioeducativas pelos mesmos e que, devido às ações de intervenções implementadas no quadro das medidas judiciais, haviam sido reinseridos no ambiente escolar. Assim, quatro dos adolescentes investigados foram recrutados em um Programa Socioeducativo de Semiliberdade e dois em um Programa de Liberdade Assistida, ambos sediados na cidade de Ribeirão Preto-SP.

Na Tabela 1 estão sumarizadas algumas informações acerca da escolarização dos adolescentes investigados.

Nota-se que, à exceção de Renan, os adolescentes passaram por diversos estabelecimentos escolares desde a creche até sua última escola. Por ocasião da investigação, todos estavam em séries incompatíveis às suas idades, evidenciando a defasagem escolar.

Também participaram da pesquisa um responsável por cada um dos adolescentes investigados $(n=6)$, junto aos quais se buscaram dados complementares acerca do percurso escolar, acrescentando informações sobre fatos, eventos, datas e locais relacionados.

Tabela 1

Caracterização dos adolescentes participantes da pesquisa.

\begin{tabular}{c|c|c|c|c|c} 
Participantes* $^{*}$ & Idade & $\begin{array}{c}\text { Ano } \\
\text { escolar }\end{array}$ & $\begin{array}{c}\text { Reprovação } \\
\text { (anos) }\end{array}$ & $\begin{array}{c}\text { Defasagem } \\
\text { (anos) }\end{array}$ & $\begin{array}{c}\text { Escolas } \\
\text { frequentadas }\end{array}$ \\
\hline Willian & 18 & $1^{0} \mathrm{EM}^{* *}$ & 01 & 03 & 10 \\
\hline Cadu & 18 & $8^{0}$ & - & 05 & 08 \\
\hline Raul & 16 & $6^{0}$ & 04 & 04 & 07 \\
\hline Gabriel & 18 & $7^{0}$ & 02 & 05 & 05 \\
\hline Leo & 17 & $7^{0}$ & 01 & 04 & 04 \\
\hline Renan & 14 & $7^{0}$ & 01 & 02 & 01 \\
\hline
\end{tabular}

${ }^{*}$ Os nomes são fictícios; ${ }^{*}$ EM - Ensino Médio. 


\section{INSTRUMENTOS}

Foram elaborados dois roteiros de entrevistas semiestruturados, sendo um para os adolescentes e outro para os responsáveis, com o objetivo de desencadear as narrativas sobre o percurso escolar e a trajetória de escolarização. As questões norteadoras se espelharam nas variáveis colocadas na literatura como relevantes na interação das crianças/adolescentes com a instituição escolar, abrangendo relacionamentos, afetos, atitudes e comportamentos nesse ambiente. Ressalta-se que a forma semiestruturada colabora na investigação de determinados aspectos afetivos e valorativos pesquisados junto aos informantes, que determinam significados pessoais atribuídos às experiências; isso é favorável também para se observar a percepção dos adolescentes daquilo que estão narrando (BONI; QUARESMA, 2005).

\section{PROCEDIMENTOS}

O projeto da pesquisa foi primeiramente submetido ao Comitê de Ética da Faculdade de Filosofia, Ciências e Letras de Ribeirão Preto da Universidade de São Paulo, tendo sido avaliado e aprovado. Para os responsáveis pelos adolescentes foi apresentado um Termo de Consentimento Livre e Esclarecido e para os adolescentes o termo foi de assentimento. quanto às instituições envolvidas (Programa de Semiliberdade, Programa de Liberdade Assistida e Estabelecimentos Educacionais), essas receberam um documento esclarecendo a pesquisa e solicitando a autorização para a realização da mesma. Conseguidas as devidas autorizações, os participantes foram entrevistados com o auxílio dos roteiros de entrevista. As entrevistas foram gravadas. Todo o material foi transcrito na íntegra.

Com base nas informações fornecidas nas entrevistas, especialmente junto aos responsáveis, identificaram-se os estabelecimentos educacionais frequentados pelos adolescentes ao longo de suas trajetórias escolares. Esses estabelecimentos (22 no total) foram visitados, no decorrer da pesquisa, com vistas a obter informações complementares sobre os adolescentes. Nesses se teve acesso aos documentos escolares (históricos, livros de anotações, cadernetas, entre outros) relativos aos participantes, quando estudantes. Os dados obtidos por meio da análise documental foram organizados em fichas. 
O material das entrevistas e da análise documental, para cada adolescente, foi reunido de modo a compor um corpus sobre o qual se realizou uma primeira análise. Os dados decorrentes das entrevistas foram tratados mediante análise de conteúdo, definida por Bardin (1977, p. 42) como:

[...] um conjunto de técnicas de análise das comunicações visando obter, por procedimentos, sistemáticos e objetivos de descrição do conteúdo das mensagens, indicadores (quantitativos ou não) que permitam a inferência de conhecimentos relativos às condições de produção/recepção (variáveis inferidas) destas mensagens.

Após leituras sucessivas, procedeu-se a redução dos dados com o intuito de sintetizar o material coletado às suas partes mais relevantes e pertinentes aos objetivos da pesquisa, estabelecendo as primeiras categorias sintéticas.

O cruzamento dos dados coletados nas entrevistas realizadas com os adolescentes, em conjunto com os coletados por meio das entrevistas com os responsáveis, e as informações contidas nos documentos institucionais consultados concorreram para uma descrição do percurso de escolarização dos adolescentes e para a compreensão do processo de escolarização dos mesmos (ESTERLE-HEDIBEL, 2003). Vale frisar que comparando as informações fornecidas nas diferentes entrevistas com as oriundas dos documentos escolares consultados, as datas e períodos relatados pelos adolescentes e responsáveis nem sempre coincidiam, revelando imprecisões, com relatos cheios de idas e vindas. De todo modo, essa característica não invalidou as informações e, ao contrário, evidenciou como o processo de contar experiências subjetivas não é linear, pois é perpassado pelas interpretações e (re)construções que os sujeitos fazem de sua história ao narrá-la (CARRA, 2001).

Posteriormente, o material relativo aos seis adolescentes foi comparado, procedendo-se ao agrupamento das informações com o objetivo de destacar semelhanças e diferenças para, a partir daí, compor novas categorias sintéticas, que foram elaboradas tanto com base em aspectos da literatura quanto no das especificidades do material coletado. 


\section{RESULTADOS}

A análise e interpretação dos dados concorreram para a identificação de dois padrões de trajetórias de escolarização, de acordo com as experiências dos adolescentes investigados: um cuja marca é a descontinuidade na qualidade das vivências escolares, havendo um período inicial experimentado como sendo positivo, mas que, em um segundo momento, passa a ser negativo; o outro, a marca é a continuidade, sendo a vivência escolar qualificada de modo preponderantemente negativo, o tempo todo, desde o início. Assim, os principais resultados são apresentados a seguir, organizados em torno dessas duas grandes categorias.

\section{Da boa à má experiência: uma trajetória escolar marcada pela descontinuidade na qualidade das vivências escolares}

Os adolescentes que integram esse grupo são Leo (L), Raul (R), Renan (Re) e Gabriel (G). Evidencia-se que significam a experiência inicial de escolarização como positiva, devido às boas lembranças associadas à entrada na escola. Falam muito de brinquedos, brincadeiras, jogos, passeios e festas, parecendo indicar que a escola, num primeiro momento, ao propiciar tais atividades, alinhou-se à infância, de um modo lúdico. Comentam, por exemplo: jogava futebol, jogava dama, jogava vôlei, escutava música, isso aí (Re); na hora do recreio batia figurinhas, jogava dama $(G)$.

A base dessa boa qualidade parece ter sido as boas relações com os professores e funcionários, baseadas na comunicação. Os adolescentes destacam boas recordações dos relacionamentos interpessoais que estabeleceram no ambiente educacional, especialmente com os professores: [...] era legal comigo, me tratava bem, falava coisas, sabe, da hora pra mim, [...] as pessoas me respeitavam (L); eu sempre me dei bem, [...], a fessora [sic] até morreu já. Vixi! Ela era da hora (R). Percebe-se que relações interpessoais positivas parecem gerar sentimento de apreço, de (re)conhecimento e, por consequência, a percepção de ser tratado de maneira personalizada. Interessante notar que os adolescentes se lembram de detalhes de alguns professores e das matérias que lecionavam, inclusive, referindo-se a eles nominalmente.

A avaliação positiva das relações também parece se apoiar na percepção do esforço observado nos profissionais em ensinar e na 
disponibilidade para ajudar no processo de aprendizagem, [...] quando eu não sabia muito en chamava "e aí senhora!", ela ajudava, falava: "se precisar pode chamar" (R).

Nota-se, todavia, que prevalece um baixo desempenho, mas este, nesse momento, não é relevante a ponto de desqualificar a vivência escolar. Com exceção de Gabriel, os desempenhos de Leo (L), Raul (R) e Renan (Re) foram muito baixos desde o começo, marcados por dificuldades de aprendizagem e atrasos nas aquisições esperadas em relação aos grupos de referência, malgrado o investimento de alguns profissionais da escola e dos esforços e desejo pessoal em aprender. É relevante frisar quão conscientes parecem esses adolescentes de seu baixo desempenho e de suas dificuldades em aprender. Para lidar com esse fato, a melhor saída parece ter sido assumir uma baixa expectativa sobre si mesmo: [...] eu tirava pouco, tá bão [sic], melhor do que tirar zero (R).

Ter bom desempenho, entretanto, acresce à vivência escolar elementos positivos, como o interesse pelos conteúdos aprendidos. No caso de Gabriel, por exemplo, o empenho dos profissionais da educação para fazê-lo aprender resultou em aquisições e no próprio gosto pelo estudo, [...] e u gostava mais de Lingua Portuguesa, de escrever. De História, ela passava texto, aí cêe [sic] tinha que resumir e escrever o texto $(G)$.

Nesse período inicial, os adolescentes, embora genericamente se concebam como "bagunceiros", oferecem informações que permitem vislumbrar que o comportamento de bagunça não adentrava a sala de aula ou este não implicava em confrontar a autoridade dos professores. Relatam que cumpriam com as tarefas que eram exigidas e que, em sala de aula, [...] ficava um anjo, não tinha uma professora que falava mal, falavam: "ah! O Leo é quieto" (L); eu ficava bagunçando, mas eu sempre fiz a lição, [...] se falava as coisas, num respondia não $(G)$. Assim, pode-se pensar que tais adolescentes apresentavam um comportamento aceitável pela escola, ou seja, eram suficientemente disciplinados. Tal funcionamento social serviu, inclusive, para protegê-los da atribuição de rótulos negativos que poderiam ter-lhes sido postos nessa época, em decorrência de suas participações em determinados eventos negativos como, por exemplo, desavenças com alguns professores e colegas.

Nesse panorama inicial, nota-se a vinculação à escola, principalmente por intermédio da vinculação às pessoas/profissionais das respectivas instituições. Com o passar do tempo, entretanto, ocorrem mudanças nesse 
panorama, mediante as quais a experiência positiva vai se desqualificando devido, principalmente, à deterioração da relação com os professores. Para esses adolescentes, os professores passam a apresentar distanciamento/ frieza no modo de interagir e descompromisso, falta de esforço (ou de disponibilidade) para efetivamente ensinar (ou para criar condições de aprendizagem para os alunos). Argumentam que: [...] não ensinava direito, num ligava pros [sic] alunos, mostrava as coisas, ensinava mais por cima, gritava com os outros, se perguntava, falava que não ia explicar de novo (G).

Raul, Renan e Gabriel referem, também, como aspecto negativo, a existência de um clima escolar hostil, seja porque se instala entre alunos e professores uma relação de rivalidade, seja porque na escola prevalece a desordem, sugerindo a existência de autoridades fracas e/ou descompromissadas com a manutenção de um clima regrado, favorável à aprendizagem. Ah, tinha uns [alunos] que xingava [sic] o professor, o professor xingava o aluno. Falava de dar tapa, tacar cadeira, esses negócios, tacar apagador (Re); [...] era bagunça o dia inteiro. Quando en queria faz̧er lição, não deixavam eu estudar, ficavam conversando, aí eu falava: "ab! Também não vou fazer nada não!” (G). Com essas vivências na escola, a apreciação negativa se generaliza, se estendendo à instituição como um todo, [...] vixi, um lixo! (L); [...] nem a comida era boa (G).

Assim, os adolescentes desse grupo vivem uma alteração em termos da qualidade das experiências que predominaram na primeira etapa de seu processo de escolarização. Para Leo (L) e Raul (R), essa mudança aparece atrelada principalmente a eventos que colocaram em evidência a não aprendizagem (as reprovações, principalmente) e a defasagem idadesérie (também decorrente de uma frequência escolar irregular). Eventos de natureza familiar, tais como separações, falecimento de cuidadores e mudanças de residência e de escola também parecem ter contribuído para o desengajamento escolar e a evasão dos mesmos. No período em que se encontravam evadidos foram apreendidos por roubo e receberam medida socioeducativa de internação (Raul) e semiliberdade (Leo). Renan (Re), por sua vez, estudou em apenas uma escola, apresentando boa frequência, porém baixo desempenho que culminou em reprovação na $4^{a}$ série. Após a reprovação, passou a apresentar comportamento considerado indisciplinado, o que ocasionou sua transferência para outra escola. Entretanto, ele interpretou esse ato como uma expulsão e evadiu, sendo nesse período detido e internado provisoriamente por tráfico de drogas. 
Já para Gabriel (G), a alteração na qualidade da vivência escolar parece mais propriamente atrelada à mudança de escola e à não adaptação ao novo ambiente. Ele começou a apresentar frequência irregular e envolvimento em brigas, o que gerou outras três mudanças de escola, até que evadiu e foi detido por tráfico de drogas, decorrendo desse ato a aplicação da medida socioeducativa de Liberdade Assistida.

À parte as peculiaridades nas trajetórias, há que se notar, para os adolescentes desse grupo, a existência de um processo de afastamento gradativo do ambiente escolar, iniciando-se com faltas reiteradas, nos casos de Leo (L), Raul (R) e Gabriel (G); ou um afastamento abrupto no caso de Renan (Re), que converge para a evasão. No período em que se encontram evadidos cometem atos infracionais pelos quais são apreendidos e receberam medidas socioeducativas. Os elementos que parecem concorrer para tal processo são o baixo desempenho [ou, ao menos, a queda nesse, no caso de Gabriel (G)], e a instalação de conflitos mais marcados e/ou frequentes nas relações interpessoais: com pares nos casos de Leo (L) e de Gabriel (G); e com as figuras de autoridade (professores e funcionários) nos casos de Raul (R) e Renan (Re). Os três elementos - irregularidade na frequência/afastamento da escola, baixo desempenho e relacionamentos conflitivos (não necessariamente nessa ordem) - parecem se ligar à guinada na qualidade atribuída à experiência de escolarização.

É importante frisar que as informações oferecidas pelas famílias de Leo (L), Raul (R), Renan (Re) e Gabriel (G) corroboram as informações oferecidas pelos adolescentes, indicando uma trajetória de escolarização caracterizada por um início positivo e uma mudança subsequente nesse valor.

\section{A má experiência desde o início: uma trajetória escolar marcada pela continuidade da qualidade negativa das vivências escolares}

Os adolescentes que integram esse grupo são Cadu (C) e Willian (W). Identifica-se que para eles a experiência escolar é, de modo geral, negativa e, dialeticamente, parece atrelar-se a um sentimento de mal-estar, de desgosto pela escola, [...] queria ir embora [da escola] de tudo quanto é jeito (C), [...] nunca gostei da escola não, senhora, não queria saber de escola não, de estudar, queria estar na rua (W). A experiência assim concebida parece ligar-se, essencialmente, a interações negativas com os professores, descritas pelos 
adolescentes desse grupo, como se professores e alunos fossem rivais, adversários que se enfrentam, conforme sugere seus relatos: [...] tinha uns professor [sic] que eu não gostava muito, também, que era arrogante [sic] (C). Nenhum professor tinha paciência comigo, eu não gostava de ninguém, não! (W). Nas falas, destaca-se a adjetivação dos professores como "arrogantes", o que sugere uma percepção de distanciamento. Da mesma forma, indicam sentirem-se inferiorizados pelos professores, concebendo-os enquanto pessoas não confiáveis. Porque tem professor que não é santinho também não! (C); [...] eu aprendi isso aí é eles [professores] na deles e eu na minha! (W).

Referem ainda perceberem os professores como não interessados, não preocupados com a aprendizagem dos alunos. De acordo com seus relatos, nota-se reiteradamente a convivência com professores pouco sensíveis às suas dificuldades de aprendizagem e, portanto, pouco compromissados em criar condições para que aprendessem de fato. Professor nem liga pra nós, nem liga! [...] Se você num entende você fica sem saber, dai assim, eles passa o cê [sic] de ano, de uma hora pra outra, sem ocê [sic] saber nada (C). A matéria, na mente não passava, ai eu já chapava, né? E eles [professores] achava [sic] que era de propósito, aí eles já ficava bravo! [sic] (W). As verbalizações denotam uma espécie de desespero nos adolescentes que, frente aos desafios e dificuldades de aprendizagem, parecem sentir-se sozinhos, desamparados, porque não receberam a ajuda de que necessitam.

Observa-se, ainda, que para os adolescentes o baixo desempenho é evidente, porém esse não é institucionalizado, não gera reprovação; ao contrário do que se passa para o grupo anterior, esse fato parece contribuir para que a experiência seja negativa: avançar nos anos escolares sem saber nada é por eles interpretado negativamente, pois parecem conceber essa ação como mais um indicador da falta de compromisso da equipe escolar com a aprendizagem.

No caso de Cadu (C), a defasagem idade-ano escolar que apresenta deve-se mais propriamente ao fato de iniciar o ensino fundamental com nove anos e de ter cursado o primeiro ano por duas vezes. Daí em diante, segue estudando sem ser reprovado até o sétimo ano, com 16 anos. Nesse momento, evade da escola pela primeira vez e é, então, detido por assalto. Daí, inicia-se um ciclo de idas e vindas a diferentes escolas, sempre evadindo, até a desistência dos estudos, aos 18 anos (momento em que participa da pesquisa). 
Com relação a Willian, esse cursa de modo ininterrupto do primeiro ao quinto ano, mantendo o conceito "satisfatório" no seu desempenho. No sétimo ano, com 12 anos de idade, é retido, pela primeira vez, por baixa frequência. Desse ponto em diante, consegue completar apenas mais um ano, o oitavo, aos 14 anos. O nono ano foi iniciado quatro vezes, porém não é completado devido à frequentação irregular, até a mais recente desistência, aos 17 anos (momento em que participa da pesquisa). O delito de tráfico pelo qual encontrava-se em medida socioeducativa acontecera aos 16 anos, período no qual estava evadido da escola.

Os adolescentes também descrevem o ambiente escolar como altamente confuso, desordenado, apontando que tal percepção também concorre para que a experiência seja negativa. Fazem relatos indicando que, em suas experiências, a escola constituiu-se como um lugar onde tudo podia acontecer, devido à falência de regras que limitassem os acontecimentos, sendo mais ou menos críticos com relação a isso: [...] ali era todo mundo que faz̧ia bagunça. Ali não é escola [...]. Ali é um parque de diversão (C). Nesse contexto, é interessante notar que os adolescentes relatam a ocorrência de muitas brigas entre pares, nas quais também se envolviam, sendo que estas, aparentemente, aconteciam, na maior parte do tempo, sem mediação de adultos. Faz̧ia muita bagunça na classe, né? [sic]. Brigava muito também. Ah, enturmava com os outros da classe, ficava brigando (C).

\section{DISCUSSÃO}

O presente estudo examinou as experiências escolares de um grupo de adolescentes em conflito com a lei, visando descrever a trajetória escolar e compreender suas experiências relacionadas ao processo de escolarização, considerando haver, na literatura científica, uma lacuna na produção de conhecimento no tocante a esses aspectos específicos. Destaca-se que o papel da escola, juntamente com a família, consiste em proporcionar condições, por meio das vivências propiciadas, que gerem aquisições para o desenvolvimento humano (LIMA et al., 2006). Assim, é fundamental conhecer as experiências escolares dos adolescentes em conflito com a lei, para além do já sabido, atinente aos indicadores negativos da escolaridade que, em linhas gerais, caracterizam esse grupo: dificuldades 
no tocante ao desempenho, defasagem idade-escolaridade e maior risco de evasão (ASHKAR; KENNY, 2009; JANOSZ et al., 2000; JANOSZ; LEBLANC, 1999; SANDER et al., 2010). Conhecer as trajetórias escolares dos adolescentes em conflito com a lei pode oferecer pistas para a instalação das condições adequadas à escolarização dos mesmos, desde o princípio e ao longo de todo o processo, com vistas a evitar rupturas ou mudanças na qualidade da experiência educacional, conforme denotado nos resultados do presente estudo.

Para alguns dos adolescentes investigados, Leo (L), Raul (R), Renan (Re) e Gabriel (G), a experiência escolar não foi sempre negativa. Nota-se, entretanto, em suas percepções, a importância atribuída ao aspecto internacional, especialmente representado na relação com os professores, sendo este um relevante diferencial na apreciação da escola, no nível de investimento na escolarização. $\mathrm{O}$ apego/afeto positivo aos professores é importante porque representa a segurança de ter ajuda sempre que necessário (CALDWELL; WIEBE; CLEVELAND, 2006). A oferta de ajuda por parte dos professores, nos momentos de dificuldade, é interpretado pelos adolescentes como indicador de interesse e estima em relação a eles. Tal percepção parece ter sido reforçada pela existência de comunicação, caracterizada por diálogo professor-alunos, perpassado pelo oferecimento de conselhos, elogios e incentivos, por parte dos professores. Essa proximidade relacional, pautada em respeito recíproco, de acordo com a visão dos adolescentes investigados, viabilizou o vínculo escolar nesse primeiro momento identificado em suas trajetórias.

Todavia, com o passar do tempo, a boa relação se deteriorou, o que contribuiu para a transição da boa à má experiência. Na medida em que a qualidade das interações se altera no sentido de se desqualificarem, se altera também o da experiência de escolarização no grupo. Há que se notar que a qualidade das relações na escola é perpassada pelo desempenho, e pelo grau de consciência que o aluno tem desse importante aspecto de sua vida escolar. De acordo com Tucker, Zayco e Herman (2002) e Chen (2005), o desempenho é condição sine qua non à adaptação escolar (cumpre a finalidade última da escolarização). Se as aquisições acontecem, como no caso de Gabriel $(\mathrm{G})$, a ligação com a escola e com a própria escolarização parece mais forte e ultrapassa o plano dos relacionamentos pessoais. Ao contrário, se o desempenho não se dá de acordo com os parâmetros 
estabelecidos, fica difícil sustentar a vinculação tão somente nas relações humanas de qualidade, sobretudo, porque ao longo das séries o desempenho em si conta mais que tão somente o esforço pessoal para ser um bom aluno (SUH; SUH; HOUSTON, 2007).

Um problema identificado é que o desempenho insatisfatório propicia defasagens nas aquisições, que vão se acumulando com o tempo, tornando a vinculação escolar mais dependente da interação professor-aluno, que das aquisições de conteúdo, imprimindo a essas relações quase que a exclusividade pela qualidade da experiência vivenciada. Todavia, frente aos resultados apresentados, nota-se que a não aprendizagem parece não ser um foco de preocupação para a escola, pois os alunos são promovidos sem as aquisições necessárias para acompanhar os conteúdos do ano escolar seguinte.

É interessante notar que Willian (W) e Cadu (C), cujos dados permitiram descrever o segundo padrão de trajetória escolar, parecem apresentar sentimentos negativos mais intensos que Leo (L), Raul (R), Renan (Re) e Gabriel $(\mathrm{G})$ - da primeira trajetória -, os quais apresentam reprovações mais frequentes, tendo o insucesso reconhecido institucionalmente.

Fato é que os adolescentes percebem-se sem aprender e indicam possuírem muitas dificuldades, denotando quão conscientes são de suas dificuldades e do consequente baixo desempenho que apresentaram, o que torna sua vida escolar sofrível; mas, em geral, mesmo não aprendendo, eles são promovidos de ano escolar. Portanto, seria imprescindível identificar e instalar precocemente programas de ajuda suplementar às crianças que demostrem dificuldades com os conteúdos escolares, de modo a garantir não somente um relacionamento professor-aluno de qualidade, mas um desempenho satisfatório, nos parâmetros estabelecidos (GARDNER; POWELL; GRANTHAM-MCGREGOR, 2007; GREENWOOD, 2008; SHARKEY et al., 2011). Apontamentos semelhantes são feitos por Lepre (2009).

De acordo com Gardner, Powell e Grantham-McGregor (2007), ainda não está claro se um baixo desempenho conduz à frustração, que por sua vez contribui para o comportamento divergente, e consequente enfraquecimento do vínculo escolar, devido à inadaptação ao ambiente escolar, ou se um vínculo escolar empobrecido afeta o desempenho escolar, ou, ainda, se haveria uma interação bidirecional entre estes fatores. Lepre 
(2009) aposta que grande parte dos problemas de aprendizagem é decorrente das relações de baixa qualidade que se estabelecem no cotidiano escolar. Nesse sentido, verificou-se, especialmente para o grupo aglutinado em torno da segunda trajetória descrita, composto por Cadu (C) e Willian (W), o quanto interações ruins, no ambiente escolar, desde o início, propiciam uma espécie de desgosto pela escola e, quando não, a instalação de um valor negativo atribuído à escola, que sustenta um sentimento de rejeição, tal qual preconizado por LeBlanc (1994) e Van Der Laan, Blom e Kleemans (2009). Esses autores estabelecem a seguinte corrente causal: desempenho escolar fraco, desgosto pela escola, rejeição pela autoridade escolar, comportamento infracional. Os dois adolescentes acima mencionados denotaram apresentar pouco respeito pelas autoridades escolares, notadamente os professores, e respondiam mal a estilos de ensino mais autoritários. Em alguns momentos, entendiam que os professores agiam com rivalidade, desrespeito, desafeto, de maneira descompromissada e distante, o que não elimina, mas afeta sobremaneira a possibilidade de permanecer na escola e, por conseguinte, o próprio processo de escolarização. Assim, quando a relação é percebida, principalmente, como negativa, de rivalidade, pode ocorrer a manifestação de violência pelos alunos ou pelos professores, mediante estabelecimento de regras inapropriadas, controle excessivo e punições inadequadas/exageradas, para disciplinar (OLIVEIRA; MARTINS, 2007).

Fatores do ambiente escolar, como um clima hostil ou desfavorável à aprendizagem e à boa convivência, por exemplo, foram relatados pelos adolescentes enquanto impedidores de permanência na escola, especialmente por aqueles que tiveram um percurso escolar tal que descrito na segunda trajetória: Willian (W) e Cadu (C). A ausência de organização do ambiente escolar e o enfraquecimento da autoridade escolar, enquanto agente de veiculação e vigilância de regras de convivência pertinentes, constituem elementos contextuais que incrementam os riscos para a desadaptação escolar, contribuindo para a manifestação de problemas de comportamento, desvinculação e até mesmo a prática de atos infracionais dentro e fora da escola. Na literatura já se sublinhou que a caoticidade do sistema normativo da escola e a possibilidade de violência entre pares interferem diretamente na motivação para a aprendizagem, desempenho escolar e social (WYNNE; JOO, 2011). 
Ademais, um ambiente escolar violento, tal como descrito por alguns dos adolescentes, parece ter reforçado neles a manifestação de comportamentos também assinalados por aspectos de agressividade. Segundo Patterson, DeBaryshe e Ramsey (1989), o comportamento antissocial se desenvolve na escola quando, ao expressar comportamentos agressivos, desobedecendo às regras escolares e se negando a colaborar, o aluno sofre a rejeição dos colegas e professores e, em seguida, sentindo o fracasso, tanto acadêmico como relacional, o adolescente abandona a escola em busca de grupos com história similar.

É interessante notar que todos os adolescentes investigados foram apreendidos por delitos cometidos durante o período de evasão escolar. $\mathrm{O}$ afastamento da escola, por expulsão ou por processos sutis de exclusão (baixo desempenho, relação conflituosa entre professores e alunos, clima escolar ruim etc.), configura-se em um marco importante para a entrada ou para o agravamento da conduta delituosa, porque parece tornar os adolescentes mais vulneráveis, pelo tempo ocioso, sem supervisão, e ligação com pares divergentes, nesse período sem atividades (PATTERSON, 1992). Estar fora da escola, também parece aumentar a vigilância das agências oficiais de controle (polícia) sobre tais adolescentes, o que incrementa as chances deles serem pegos e apreendidos, gerando um ciclo de consequências negativas que irá piorar a situação escolar dos mesmos (BAZON et al., 2011).

Tem-se, portanto, que a frequência escolar, per si, pode constituir-se em um fator de proteção do adolescente quando esta fortalece sua rede prossocial (PASSAMANI; ROSA, 2009) e garante uma rotina minimamente convencional (JANOSZ; LEBLANC, 1999). Faz-se necessário, todavia, discutir que tipo de escola está sendo oferecida aos adolescentes, em termos de qualidade das experiências proporcionadas. Será que é uma instituição à qual se pode creditar a promoção e o fortalecimento de redes pró-sociais? Existe a disponibilização de adultos, enquanto modelos de comportamento e abertos ao relacionamento com os alunos? A instituição dispõe de profissionais competentes para identificar precocemente dificuldades de aprendizagem e criar condições diferenciadas para determinados alunos aprenderem? Para além do conhecimento produzido com a presente pesquisa, esta lança essas questões para as próximas investigações. 


\section{CONSIDERACְÕES FINAIS}

Os resultados encontrados indicam que os adolescentes em conflito com a lei investigados apresentaram um percurso escolar, em geral, marcado pela frequentação de muitos estabelecimentos educacionais, dificuldades de aprendizagem, defasagem idade-ano escolar, reprovações e evasão, reiterando resultados de pesquisas já realizadas. Porém, uma novidade foi o fato de a investigação ter trazido à luz o modo como o processo de escolarização foi experienciado, indicando aspectos que parecem muito relevantes na explicação de por que o percurso escolar desse segmento assim se dá. Foram identificados dois padrões de trajetórias de escolarização, que os diferenciava: um em que a trajetória escolar é marcada por experiências positivas que se tornaram negativas, e outro marcado por um aspecto de continuidade, com experiências negativas desde o princípio. Pôde-se assim vislumbrar os motivos pelos quais os adolescentes, provavelmente, deixam de frequentar a escola.

Depreende-se com a discussão dos resultados a necessidade de os estabelecimentos educacionais atenderem às condições que evitam a evasão escolar e, paralelamente, contribuem para a não reincidência daqueles alunos que já foram apreendidos por algum delito. Como os adolescentes em conflito com a lei estão em desenvolvimento, pode-se evitar ou superar a prática de infrações se lhes forem assegurados meios adequados para tanto, tendo a escola um papel importante a desempenhar nesse quadro (PRIULI; MORAES, 2007). Ela pode exercer papel ativo e fundamental, uma vez que a intervenção de ajuda e de prevenção não contempla apenas a desvinculação dos adolescentes do ato infracional, mas remete à sua integração social, o que, em seu turno, remete à vinculação escolar. São necessárias, portanto, intervenções de grande impacto na vida dos adolescentes, sendo a ausência de um projeto de escolarização um entre tantos fatores relacionados à vulnerabilidade que apresentam.

Em termos de limitações do estudo, é importante reconhecer que, embora este tenha propiciado a obtenção de informações aprofundadas acerca das experiências de escolarização dos sujeitos pesquisados, a abordagem qualitativa utilizada na investigação não permite a generalização dos resultados e conclusões. O estudo também se limitou a investigar sujeitos do sexo masculino. Estudos futuros, portanto, devem ser concebidos de 
modo a ultrapassar essas limitações, testando num universo maior e mais diversificado os achados aqui descritos.

Ademais, tendo sido o foco desta investigação o contexto escolar, não se observaram de modo sistemático os impactos diretos e indiretos de outras variáveis, extraescolares, que podem interferir na escolarização, tais como as pertencentes à família, aos pares e à própria comunidade. Essa é uma questão relevante porque a combinação de variáveis de risco pode ampliar a conduta infracional e a própria desadaptação escolar. 


\section{REFERÊNCIAS}

ASHKAR, P.; KENNY, D. T. Young offenders' perceptions of school: an ecological analysis. Psychiatry Psychology and Law, London, v. 16, n. 3, p. 355-368, 2009. http:/ /dx.doi. org/10.1080/13218710902930283

ASSIS, S. G.; CONSTANTINO, P. Perspectivas de prevenção da infração juvenil masculina. Ciência e Saúde Coletiva, Rio de Janeiro, v. 10, n. 1, p. 81-90, 2005. http://dx.doi.org/10.1590/ S1413-81232005000100014

BARDIN, L. Análise de conteúdo. Lisboa: Edições 70, 1977.

BAZON, M. R. et al. Adolescentes em conflito com a lei, padrões de comportamento infracional e trajetória da conduta delituosa: um modelo explicativo na perspectiva desenvolvimental. Revista Brasileira Adolescência e Conflitualidade, São Paulo, v. 5, n. 2, p. 59-87, 2011.

BONI, V.; QUARESMA, S. J. Aprendendo a entrevistar: como fazer entrevistas em Ciências Sociais. Em Tese, Florianópolis, v. 2, n. 3, p. 68-80, 2005.

CALDWELL, R. M.; STURGES, S. M.; SILVER, N. C. Home versus school environments and their influences on the affective and behavioral states of African American, Hispanic, and Caucasian juvenile offenders. Journal of Child and Family Studies, New York, v. 16, n. 1, p. 125-138, 2007. http://dx.doi.org/10.1007/s10826-006-9073-6

CALDWELL, R. M.; WIEBE, R. P.; CLEVELAND, H. H. The influence of future certainty and contextual factors on delinquent behavior and school adjustment among African American adolescents. Journal of Youth and Adolescence, New York, v. 35 , n. 4, p. 591-602, 2006. http://dx.doi.org/10.1007/s10964-006-9031-z

CARRA, C. Delinquance juvenile et quartiers "sensibles". Paris: L'Armattan, 2001.

CHEN, J. J. L. Relation of academic support from parents, teachers, and peers to Hong Kong adolescents' academic achievement: the mediating role of academic engagement. Genetic, Social and General Psychology Monographs, Washington, v. 131, p. 77-127, 2005. PMid:16779945. http://dx.doi.org/10.3200/MONO.131.2.77-127

CONSELHO NACIONAL DE JUSTIÇA - CNJ. Panorama nacional: a execução das medidas socioeducativas de internação. Brasília: CNJ, 2012. Disponível em: <http://www. cnj.jus.br/images/pesquisas-judiciarias/Publicacoes/panorama_nacional_doj_web.pdf $>$. Acesso em: 13 fev. 2011.

DISHION, T. J. et al. Family, school, and behavioral antecedents to early adolescent involvement with antisocial peers. Developmental Psychology, Washington, v. 27, n. 1, p. 172-180, 2003. http://dx.doi.org/10.1037/0012-1649.27.1.172

ESTERLE-HEDIBEL, M. Trayectorias Delincuentes e interrupciones de escolaridad antes los 16 anos. In: CONGRESSO DE CRIMINOLOGIA DO RIO DE JANEIRO, 2003. Anais... Rio de Janeiro: [s.n.], 2003.

FORMIGA, N. Pares socionormativos e condutas desviantes: testagem de um modelo teórico. Barbarói, Santa Cruz do Sul, v. 32, n. 1, p. 28-43, 2010.

FRÍAS-ARMENTA, M.; LÓPEZ-ESCOBAR, A. E.; DÍAZ-MÉNDEZ, S.G. Predictores de la conducta antisocial juvenil: un modelo ecológico. Estudos de Psicologia (Natal), Natal, v. 8, n. 1, p. 15-24, 2003. http://dx.doi.org/10.1590/S1413-294X2003000100003 
GARDNER, J. M. M.; POWELL, C. A.; GRANTHAM-MCGREGOR, S. M. Determinants of aggressive and prosocial behaviour among Jamaican schoolboys. West Indian Medical Journal, Kingston, v. 56 , n. 1, p. 34-41, 2007.

GAZIGNATO, E. C. S. O perfil do adolescente autor de ato infracional grave, no estado de São Paulo: tendências sociodemográficas. 2006. 125 f. Monografia (Graduação em Psicologia)Universidade de São Paulo, São Paulo, 2006.

GREENWOOD, P. Prevention and Intervention Programs for Juvenile Offenders. Future of Children, Los Altos, v. 18, n. 2, p. 185-210, 2008. http:/ /dx.doi.org/10.1353/foc.0.0018 JANOSZ, M.; LEBLANC, M. Abandono escolar na adolescencia: factores comuns e trajectórias múltiplas. Revista Portuguesa de Pedagogia, Coimbra, v. 34, n. 1-2-3, p. 341-403, 1999. JANOSZ, M. et al. Predicting different types of school dropouts: a typological approach with two longitudinal samples. Journal of Educational Psychology, Arlington, v. 92, n. 1, p. 171-190, 2000. http://dx.doi.org/10.1037/0022-0663.92.1.171

LARANJEIRA, C. A. A análise psicossocial do jovem delinquente: uma revisão da literatura. Psicologia em Estudo, Maringá, v. 12, n. 2, p. 221-227, 2007.

LEBLANC, M. Self-control and social control of deviant behavior in context: development and interactions along the life course. In: WIKSTROM, P. O. H.; SAMPSON, R. J. (Orgs.). The Explanation of Crime Context, Mechanisms, and Development. New York: Cambridge University Press, 2006. p. 124-151.

LEBLANC, M. Family, school, delinquency and criminality, the predictive power of an elaborated social control theory for males. Criminal Behaviour and Mental Health, London, v. 4, n. 1, p. 101-117, 1994.

LEPRE, M. R. Reflexões sobre a indisciplina na escola. Psicopedagogia Online, [s.l.], 17 set. 2009. Disponível em: <www.psicopedagogia.com.br/artigos/artigo.asp?entrID=1167>. Acesso em: 26 jan. 2010.

LILJEBERG, J. F. et al. Poor school bonding and delinquency over time: bidirectional effects and sex differences. Journal of Adolescence, London, v. 34, n. 1, p. 1-9, 2011. PMid:20417551. http://dx.doi.org/10.1016/j.adolescence.2010.03.008

LIMA, I. M. S. O. et al. Experiências de violência intrafamiliar entre adolescentes em conflito com a lei. Revista Brasileira de Crescimento e Desenvolvimento Humano, São Paulo, v. 16, n. 2, p. 16-24, 2006.

MASCHIA, T. et al. Mapping the social service pathways of youth to and through the juvenile justice system: a comprehensive review. Children and Youth Services Review, Oxford, v. 30, n. 12, p. 1376-1385, 2008. http://dx.doi.org/10.1016/j.childyouth.2008.04.006

MUN, E. Y.; WINDLE, M.; SCHAINKER, L. M. A model-based cluster analysis approach to adolescent problem behaviors and young adult outcomes. Development and Psychopathology, New York, v. 20, n. 1, p. 291-318, 2008. http://dx.doi.org/10.1017/S095457940800014X OLIVEIRA, M. B.; ASSIS, S. G. Os adolescentes infratores do Rio de Janeiro e as instituições que os "ressocializam": a perpetuação do descaso. Caderno de Saúde Pública, Rio de Janeiro, v. 4, n. 10, p. 831-844, 1999.

OLIVEIRA, E. C. S.; MARTINS, S. T. F. Violência, sociedade e escola: da recusa do dialogo à falência da palavra. Psicologia \& Sociedade, Belo Horizonte, v. 19 , n. 1, p. 90-98, 2007. http://dx.doi.org/10.1590/S0102-71822007000100013 
PASSAMANI, M. E; ROSA, E. M. Conhecendo um programa de liberdade assistida pela percepção de seus operadores. Psicologia: Ciência e Profissão, Brasília, v. 29, n. 2, p. 330-345, 2009. http://dx.doi.org/10.1590/S1414-98932009000200010

PATTERSON, G. R. Developmental changes in antisocial behavior. In: PETERS, R. D.; MCMAHON, R. J.; QUINSEY, V. L. (Org.). Aggression and violence throughout the lifespan. Newbury Park: Sage, 1992. p. 52-82.

PATTERSON, G. R.; DEBARYSHE, B. D.; RAMSEY, E. A developmental perspective on antisocial behaviour. American Psychologist, Washington, v. 44, p. 329-335, 1989. http:// dx.doi.org/10.1037/0003-066X.44.2.329

PRIULI, R. M. A.; MORAES, M. S. Adolescentes em conflito com lei. Ciência \& Saúde Coletiva, Rio de Janeiro, v. 12, n. 5, p. 1185-1192, 2007.

SANDER, J. B. et al. A qualitative study of juvenile offenders, student engagement, and interpersonal relationships: implications for research directions and preventionist approaches. Journal of Educational and Psychological Consultation, Hillsdale, v. 20, n. 4, p. 288-315, 2010. http://dx.doi.org/10.1080/10474412.2010.522878

SHARKEY, J. D. et al. The protective influence of gangs: Can schools compensate? Aggression and Violent Behavior, London, v. 16, n. 1, p. 45-54, 2011.

SILVA, I. R. O.; SALLES, L. M. F. Adolescente em liberdade assistida e escola. Estudos de Psicologia (Campinas), Campinas, v. 28, n. 3, p. 353-362, 2011. http://dx.doi.org/10.1590/ S0103-166X2011000300007

SUH, S.; SUH, J.; HOUSTON, I. Predictors of categorical at-risk high school dropouts. Journal of Counseling \& Development, Alexandria, v. 85, n. 2, p. 196-203, 2007. http:/ /dx.doi. org/10.1002/j.1556-6678.2007.tb00463.x

TEIXEIRA, J. A.; ONOFRE, E. M. C. A escolarização de jovens autores de atos infracionais. InterMeio, Campo Grande, v. 15, n. 29, p. 164-179, 2009.

TOLEDO, G. W.; BAZON, M. R. A delinquência juvenil no estado de São Paulo: estudo de sua evolução entre 1950 e 2002. In: BIASOLI-ALVES, Z. M. N. et al. (Orgs.). Programa de Pós-Graduação em Psicologia: Livro de Artigos - Tomo II. Ribeirão Preto: Legis Summa, 2005. p. 299-309.

TUCKER, C. M.; ZAYCO, R. A.; HERMAN, K. C. Teacher and child variables as predictors of academic engagement among low-income African American children. Psychology in the Schools, Wilmington, v. 39, n. 4, p. 477-488, 2002.

VAN DER LAAN, A. M.; BLOM, M.; KLEEMANS, E. R. Exploring long-term and short-term risk factors for serious delinquency. European Journal of Criminology, London, v. 6, n. 5, p. 419-438, 2009. http://dx.doi.org/10.1177/1477370809337882

WYNNE, S. L.; JOO, H. Predictors of school victimization: individual, familial, and school factors. Crime \& Delinquency, New York, v. 57, n. 3, p. 458-488, 2011. http://dx.doi. org/10.1177/0011128710389586

ZHANG, D. et al. Truancy offenders in the juvenile justice system: a multicohort study. Behavioral Disorders, Reston, v. 35, n. 3, p. 229-242, 2010. 
Apoio financeiro: Fundação de Amparo à Pesquisa do Estado de São Paulo (FAPESP).

Recebido: $15 / 02 / 2013$

Aprovado: 25/04/2013

Contato:

Universidade de São Paulo Faculdade de Filosofia, Ciências e Letras de Ribeirão Preto Departamento de Psicologia Av. Bandeirantes, 3900, Monte Alegre CEP 14040-901 Ribeirão Preto, SP Brasil 